\title{
A case of vertebral arteriovenous fistula in a patient undergoing maintenance hemodialysis
}

\author{
Kinuko Dote ${ }^{1 *}$, Nobuyuki Takahashi ${ }^{1}$, Tomoko Niki ${ }^{2}$, Tomoya Ishiguro ${ }^{3}$ and Ichiro Shiojima ${ }^{4}$
}

\begin{abstract}
Background: Vertebral arteriovenous fistula (AVF) is an uncommon vascular disorder and defined as abnormal connections of the extracranial vertebral artery or its branches into the neighboring vein or deep venous plexus. This can be spontaneous or traumatic in origin. Spontaneous cases may be congenital or associated with dysplasia of vascular wall. Traumatic cases are due either to blunt or penetrating trauma, or iatrogenic trauma.

Case presentation: A vertebral AVF was detected by carotid duplex ultrasonography, and an endovascular treatment was successfully performed in a 72-year-old woman with 1 year history of hemodialysis.

Conclusion: An extensive observation by carotid duplex ultrasonography is needed to detect vertebral AVF in patients who have a history of dialysis catheter insertion to internal jugular vein.
\end{abstract}

Keywords: Vertebral arteriovenous fistula, Hemodialysis, Carotid duplex ultrasonography

\section{Background}

Vertebral arteriovenous fistula (AVF) is defined as abnormal connections of the extracranial vertebral artery or its branches into the neighboring vein or deep venous plexus [1]. Spontaneous cases may be congenital or associated with dysplasia of vascular wall [2]. On the other hand, traumatic cases are due either to blunt or penetrating trauma, or iatrogenic trauma [3].

The diagnosis of vertebral AVF relied on catheter angiography, but recent advances in non-invasive imaging modalities make the diagnosis much easier [4].

For the treatment of vertebral AVF, preservation of the parental artery is important and must be attempted. Endovascular treatment is a minimally invasive treatment modality and does not have the disadvantages of open surgery [5-7]. Different types of endovascular approaches, transvenous, transarterial or both with coil or balloon embolization are reported [6, 8]. We report a case of vertebral AVF in a hemodialysis patient, first

\footnotetext{
* Correspondence: doteki@kouri.kmu.ac.jp

${ }^{1}$ Department of Medicine, Kori Hospital, Kansai Medical University, 8-45

Korihondori-cho, Neyagawa City, Osaka 572-8551, Japan

Full list of author information is available at the end of the article
}

detected by the carotid duplex ultrasonography and successfully treated with endovascular therapy.

\section{Case presentation}

A 72-year-old woman with established end-stage renal disease secondary to hypertension who was on hemodialysis for 1 year using a left upper-extremity dialysis access fistula. She had a history of dialysis catheter insertion into the right internal jugular vein at the initiation of hemodialysis. On physical examination, blood pressure was $155 / 89 \mathrm{mmHg}$ and regular heart rhythm of $75 \mathrm{bpm}$. Auscultation revealed no abnormal heart sounds and lung crepitations. A neck bruit might be the only presenting sign, and there was a thrill over her right neck. Laboratory data obtained before dialysis were hemoglobin $11.8 \mathrm{~g} / \mathrm{dl}$, blood urea nitrogen $70 \mathrm{mg} / \mathrm{dl}$, creatinine $10.03 \mathrm{mg} / \mathrm{dl}$, calcium $9.6 \mathrm{mg} / \mathrm{dl}$, inorganic phosphorus $4.0 \mathrm{mg} / \mathrm{dl}$, $\mathrm{N}$-terminal pro-brain natriuretic peptide $1840 \mathrm{pg} / \mathrm{ml}$. Human atrial natriuretic peptide was $68.5 \mathrm{pg} / \mathrm{ml}$ after dialysis. Chest X-ray showed neither pulmonary congestion nor cardiomegaly, with a cardiothoracic ratio

(c) The Author(s). 2018 Open Access This article is distributed under the terms of the Creative Commons Attribution 4.0 International License (http://creativecommons.org/licenses/by/4.0/), which permits unrestricted use, distribution, and 


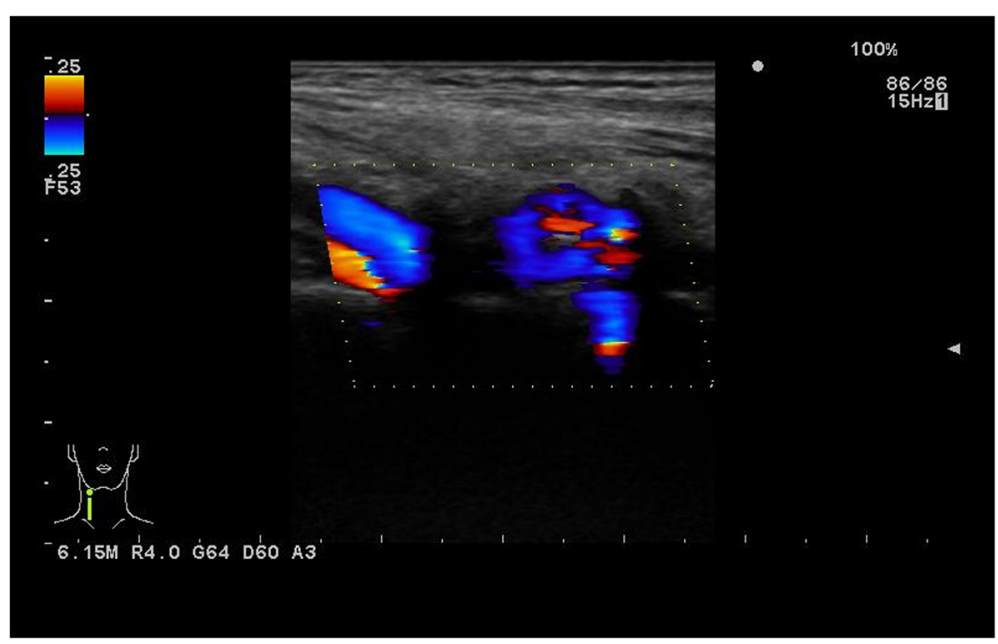

Fig. 1 Carotid duplex ultrasonography. The mosaic pattern of bloodstream in the right vertebral artery

of 54\%. Medications included ezomeprazole magnesium $20 \mathrm{mg} /$ day, nifedipine CR $40 \mathrm{mg} /$ day, doxazosin $4 \mathrm{mg} /$ day, olmesartan $40 \mathrm{mg} /$ day, azosemide $60 \mathrm{mg} /$ day, carvedilol $2.5 \mathrm{mg} /$ day, lanthanum carbonate $1500 \mathrm{mg} /$ day, sevelamer hydrochloride $750 \mathrm{mg} /$ day, and atorvastatin $10 \mathrm{mg} /$ every other day. Low molecular-weight heparin was used for anticoagulation during dialysis session. The carotid duplex ultrasonography was performed for the screening of vascular wall thickness and luminal stenosis of carotid and vertebral arteries, which detected a mosaic pattern of bloodstream in the right vertebral artery with a high peak systolic velocity of $89.6 \mathrm{~cm} / \mathrm{s}$ at the right $\mathrm{C} 6 / 7$ level and a slow peak systolic velocity of $30 \mathrm{~cm} / \mathrm{s}$ at the right $\mathrm{C} 4 / 5$ level (Figs. 1 and 2). Cervical magnetic resonance angiography (MRA) revealed a right-sided mass lesion at $\mathrm{C} 5 / 6$ level next to the right epidural venous plexus (Fig. 3). Distal right vertebral artery was not detected. Cone beam computed tomography (CT) revealed a fistulous communication between the ventromedial part of the right C5/6 level vertebral artery and the vertebral venous plexus (Fig. 4). The patient underwent a digital subtraction angiography examination to clear up the architect of the AVF and to plan treatment strategy. Injection of contrast agent to the right vertebral artery showed a single high flow side-to-side fistula at the right $\mathrm{C} 5 / 6$ level; vertebral artery flowed into the neighboring vertebral venous plexus, then drained to epidural venous plexus in the spinal canal and finally to the vertebral venous plexus outside the spinal canal via intervertebral vein, or directly drained to the subclavian vein (Fig. 5). Although diagnosis of vertebral AVF and its accurate localization were obtained by catheter

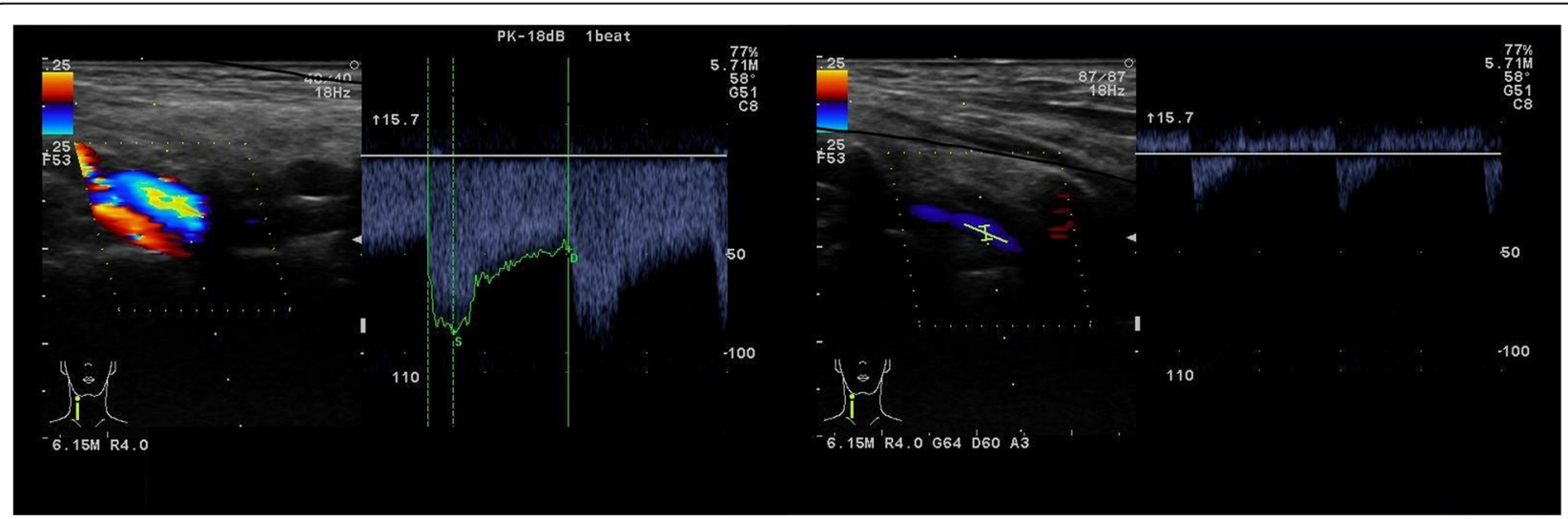

Fig. 2 Carotid duplex ultrasonography. The high peak systolic velocity of $89.6 \mathrm{~cm} / \mathrm{s}$ at the right C6/7 level (left) and the slow peak systolic velocity of $30 \mathrm{~cm} / \mathrm{s}$ at the right C4/5 level (right) 


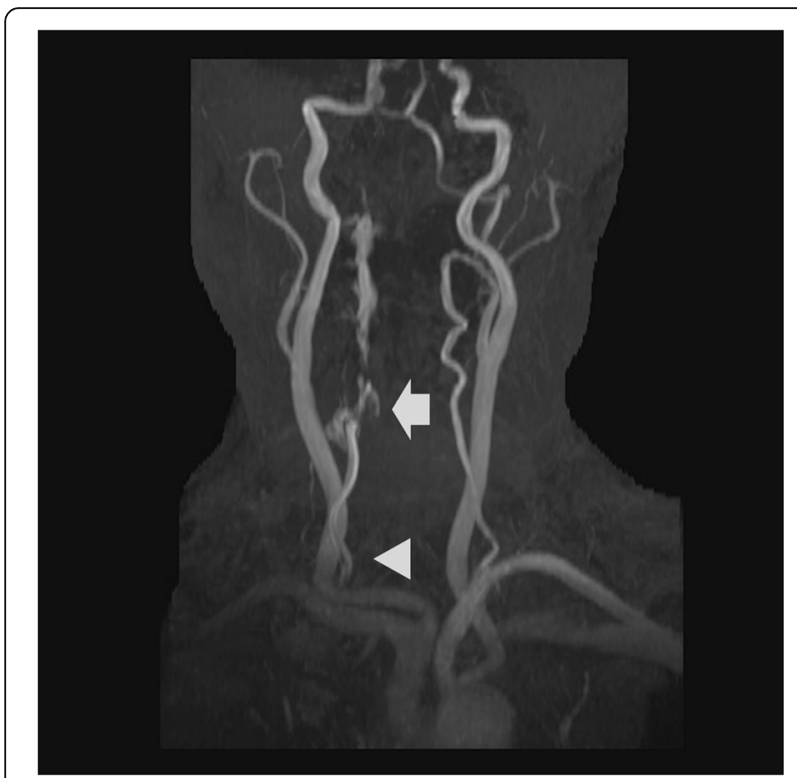

Fig. 3 Cervical magnetic resonance angiography imaging at the right C5/6 level revealed insufficient filling of the distal right vertebral artery (headed arrow) and detection of the right epidural venous plexus (arrow)

angiography, non-invasive imaging modalities such as color duplex ultrasonography, CT, and MRA can also reveal correct localization of fistula, especially duplex scan is the simplest and least invasive method. Under local anesthesia, after microcatheters

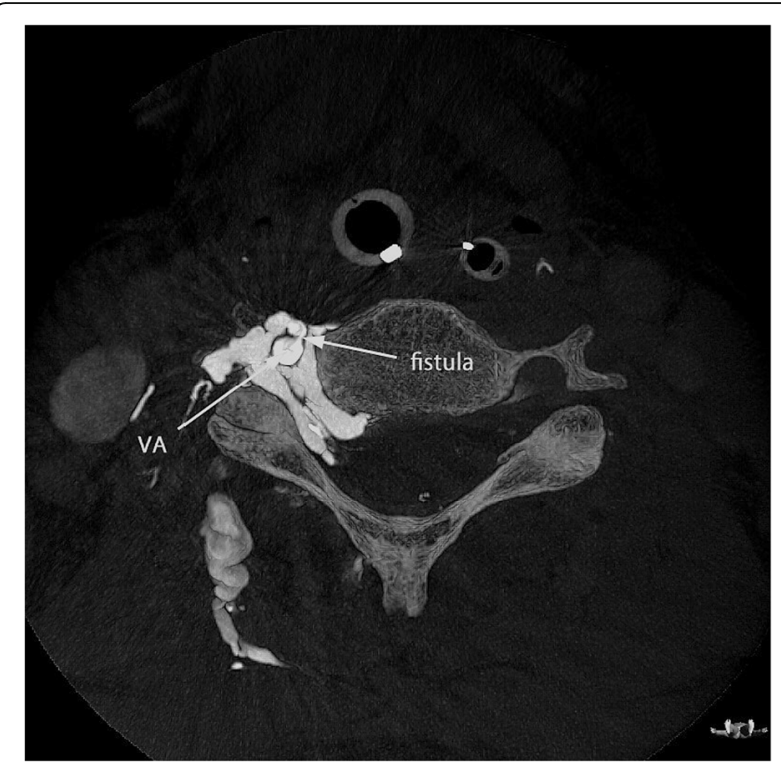

Fig. 4 Cone beam computed tomography revealed the fistulous communication (arrow) between the right C5/6 level vertebral artery (arrow) and the neighboring right vertebral venous plexus. VA, vertebral artery were inserted into the right vertebral artery and vein, the fistula was completely occluded by 18 coils from arterial side and 3 coils from venous side. The final angiogram showed no residual filling of the fistula and a normal filling of distal vertebral artery (Fig. 5). The neck thrill disappeared immediately after the procedure.

\section{Discussion}

Vertebral AVF is a rare vascular disorder and can be spontaneous or traumatic in origin [2]. Spontaneous ones are complicated by primary vascular pathologies like neurofibromatosis, fibromuscular dysplasia, Marfan's syndrome, or Ehlers-Danlos syndrome $[9,10]$. The causes of traumatic fistulas are penetrating trauma (stab wounds), blunt trauma (whiplash injury), gunshot wounds, surgical events, hyperextension injury following car accident, after nerve block injection, or by catheter insertion [2, 3]. Most traumatic vertebral AVFs involve the long second portion (intraforaminal) of vertebral artery, whereas spontaneous AVFs usually involve the third portion where the artery leaves the foramen of the atlas and enters the foramen magnum [11]. Although a spontaneous nature cannot be fully denied, fistula might have been caused by injury to the vertebral artery at the time of dialysis catheter insertion to the right neck in our case. We have investigated literatures from 1969 to 2018 by PubMed and found 31 cases describing the details of vertebral AVF that were related to catheter insertion; two of them were dialysis catheter [2, 3, 8, 12-16] (Table 1). Catheter-related iatrogenic cause is not uncommon among traumatic vertebral AVF. According to the report by Vinchon et al., 18 of 28 cases were caused by iatrogenic trauma; 14 occurred after arterial puncture during venous catheterization, 2 after direct percutaneous carotid angiography, and 2 after jugular vein puncture for Greenfield filter insertion [2]. Other causes included surgery (two), penetrating cervical trauma (three), and blunt trauma (five) [2]. The risk of arterial puncture during percutaneous internal jugular vein puncture has been markedly reduced using ultrasound guidance. Even if it does occur, development of vertebral AVF is a rare complication because vertebral artery runs posteriorly through inside of transverse foramen of cervical vertebra. However, as shown in ultrasonography obtained from a normal volunteer, vertebral artery runs quite close to internal jugular vein (Fig. 6), so that an erroneous puncture may accidentally occur. Anatomical variations such as goiter, ankylosing spondylitis, or even obesity might increase the risk of erroneous puncture [13]. In addition, it is sometimes difficult to 


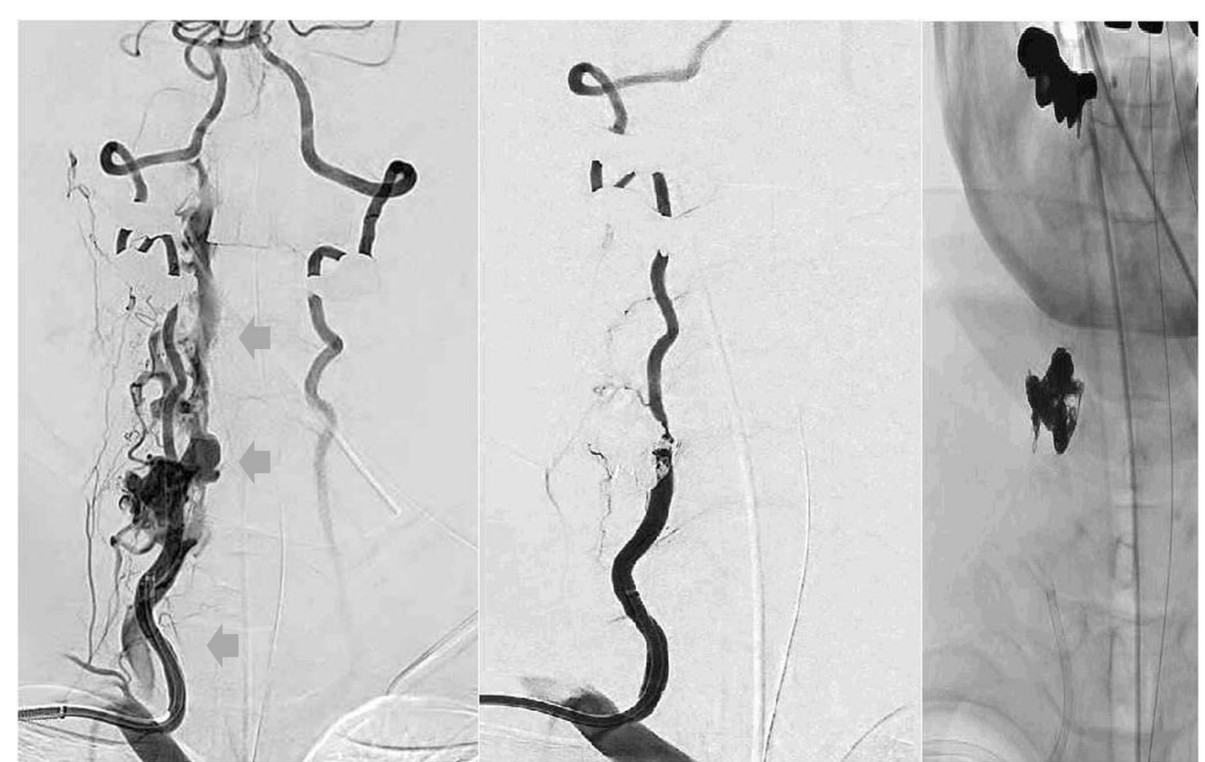

Fig. 5 Digital subtraction angiography of the right vertebral artery (anterior-posterior view) revealed a single high flow side-to-side fistula (middle arrow) between the right vertebral artery (lower arrow) and the neighboring right vertebral venous plexus and the right epidural venous plexus (upper arrow) (left). Complete obliteration of fistula (middle). Coils in the right vertebral arteriovenous fistula (right)

visualize whether the tip of the needle or catheter is remaining inside the vein even under the use of ultrasound guidance.

Symptomatology depends on the site of the vertebral AVF and the flow pattern. Most of the patients are asymptomatic, and the fistula is found after systematic auscultation [3]. Tinnitus, the most frequent symptom, is enhanced by exertion, straining, elevated blood pressure, pregnancy, and diminished or abolished by percutaneous compression or turning the head [17, 18]. Vertebrobasilar insufficiency is also common including headache and vertigo [19]. Very rarely there are symptoms of cervical radiculopathy [20]. Although the mechanism of cervical radiculopathy is often unclear, direct compression by dilated draining veins or a false aneurysm penetrating the vertebral canal are reported especially in Recklinghausen patients [21, 22]. AVF sometimes causes high-cardiac output state due to increasing venous return [23]. This is very important especially in hemodialysis patients. Because they already have AVF for hemodialysis, additional presence of AVF may cause a congestive heart failure. Fortunately, she had never suffered from heart failure because AVF was so small and cardiac output was $5 \mathrm{~L} / \mathrm{min}$.

Carotid duplex ultrasonography, MRA and CT are non-invasive and useful methods to diagnose vertebral AVF. Although ultrasound is limited by operator's ability, it is useful as the first line investigation. We found fistula incidentally by regular checkup for vascular wall thickness and luminal stenosis of carotid and vertebral arteries. The vertebral AVF was detected by a mosaic pattern of blood flow and the change in peak systolic velocity in the vertebral artery at C5/6 level, which was further confirmed by MRA and CT. The use of MRA in imaging the vertebral artery is well established [24]. Contrast enhanced MRA was not performed in our case to avoid exposure to gadolinium contrast agent in dialysis patients, but MRA clearly demonstrated fistulous connection of arterial flow to vertebral and epidural venous plexus.

The goal of the treatment is occlusion of the fistula site and preservation of the patency of vertebral artery. Open surgical repair of vertebral artery injuries is extremely challenging because of multiple factors; the most significant one is obtaining adequate exposure with proximal and distal vascular control [24]. Surgical treatment of extracranial vertebral artery has greatly evolved in recent years, now primarily involves endovascular transcatheter therapies including coil or balloon occlusion of the fistula and stent-assisted arterial reconstruction [24]. Intravascular coils with smaller diameters than the balloon may be used when the orifice of the fistula is too small to allow safe inflation of the detachable balloon [9]. In our case, the embolic materials were placed both proximal and distal to the fistula via both vertebral artery and vein for the complete elimination of the fistula. 


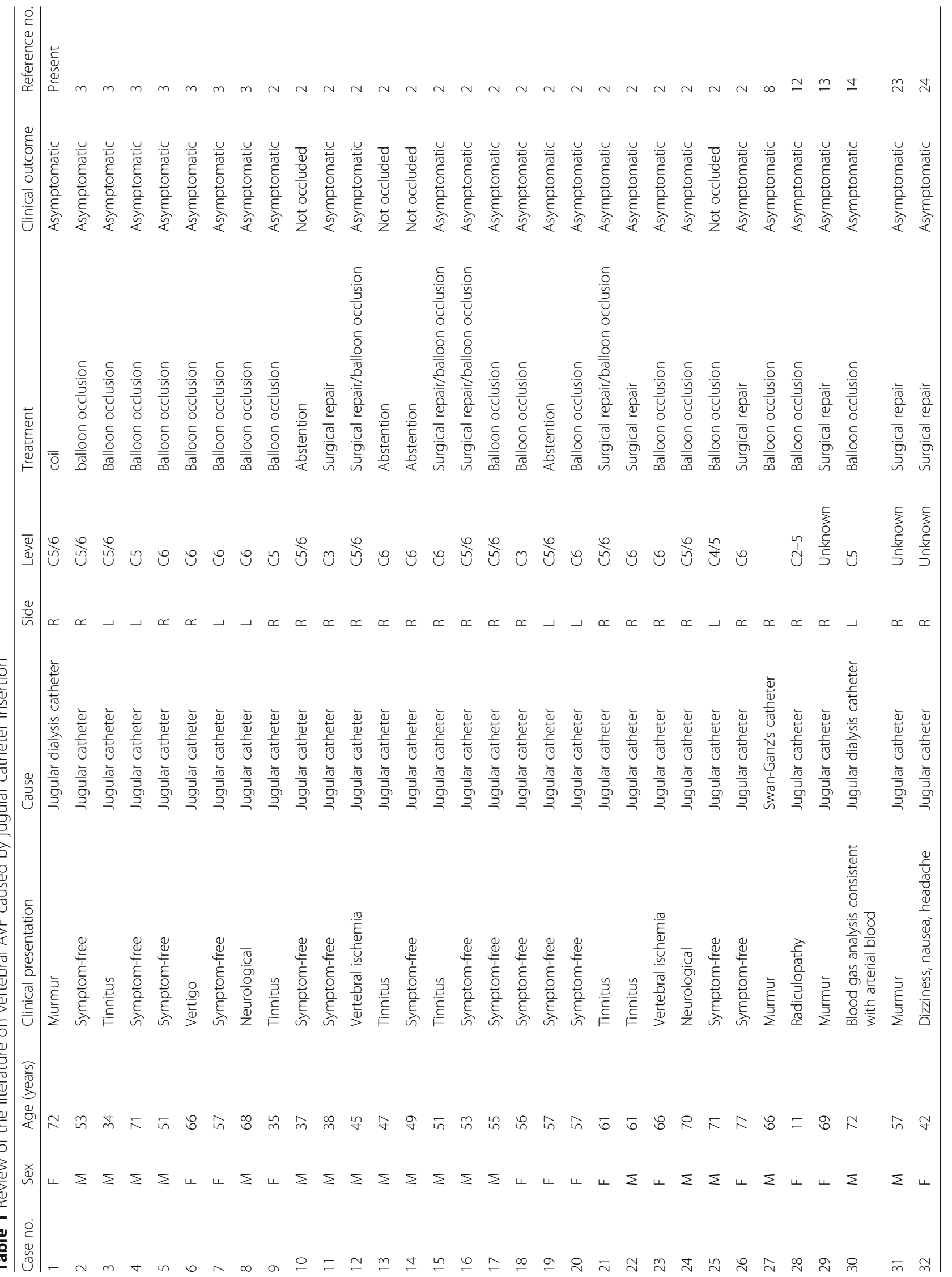




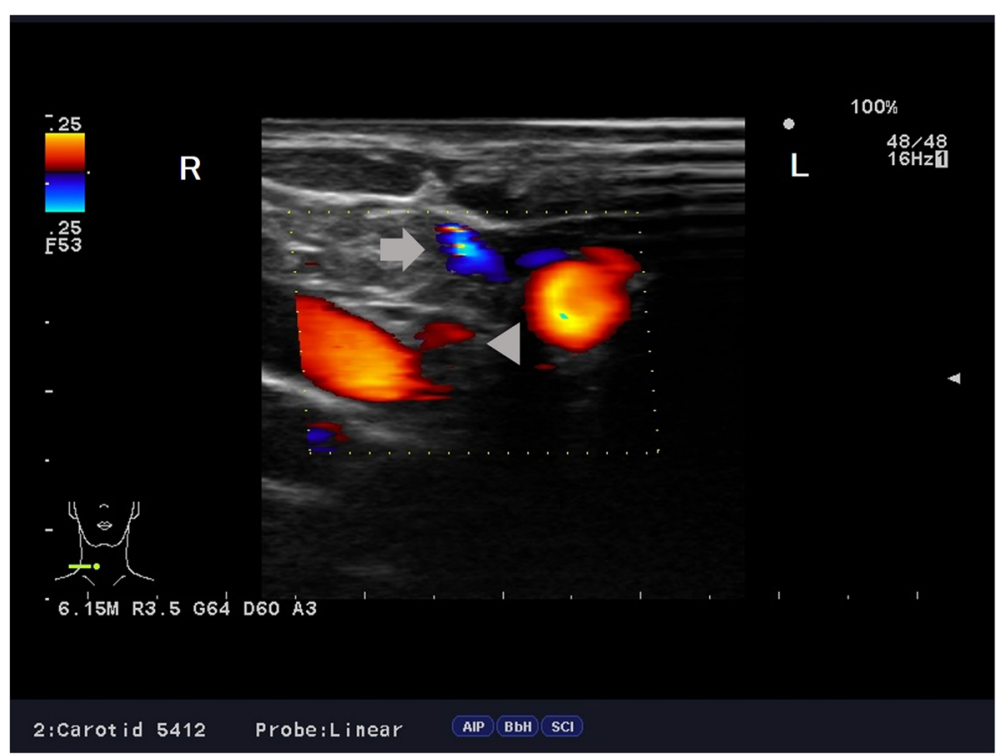

Fig. 6 Carotid ultrasonography of the right vertebral artery (headed arrow) and the right internal jugular vein (arrow) obtained from a normal volunteer

\section{Conclusion}

A case of vertebral AVF was first confirmed by systemic auscultation and carotid duplex ultrasonography. We should be aware of vertebral AVF in patients undergoing hemodialysis who had a history of dialysis catheter insertion to the neck.

\section{Abbreviations}

AVF: Arteriovenous fistula; CT: computed tomography; MRA: magnetic resonance angiography

\section{Availability of data and material}

Data sharing not applicable to this article as no datasets were generated or analyzed during the current study.

\section{Authors` contributions}

$\mathrm{KD}, \mathrm{TN}$, and $\mathrm{TI}$ performed acquisition and interpretation of the data. $\mathrm{KD}$ drafted the manuscript and is responsible for the final version of the manuscript. NT and SI supported the entire process of preparing the manuscript. All authors read and approved the final manuscript.

\section{Authors' information}

Department of Medicine, Kori Hospital, Kansai Medical University.

\section{Ethics approval and consent to participate}

Written informed consent was obtained from the patient for publication of this case report and any accompanying images. This project was reviewed and approved by the Kansai Medical University Review Board.

\section{Competing interests}

The authors declare that they have no competing interests.

\section{Publisher's Note}

Springer Nature remains neutral with regard to jurisdictional claims in published maps and institutional affiliations.

\section{Author details}

'Department of Medicine, Kori Hospital, Kansai Medical University, 8-45 Korihondori-cho, Neyagawa City, Osaka 572-8551, Japan. ${ }^{2}$ Department of Laboratory Medicine, Kori Hospital, Kansai Medical University, Neyagawa City,
Osaka, Japan. ${ }^{3}$ Department of Neurointervention, Osaka City General Hospital, Osaka City, Osaka, Japan. ${ }^{4}$ Second Department of Internal Medicine, Kansai Medical University, Hirakata City, Osaka, Japan.

Received: 26 March 2018 Accepted: 2 October 2018 Published online: 14 November 2018

\section{References}

1. Halbach W, Higashida RT, Hieshima GB. Treatment of vertebral arteriovenous fistulas. AJR Am J Roentgenol. 1988:150:405-12.

2. Vinchon M, Laurian C, George B, et al. Vertebral arteriovenous fistulas: a study of 49 cases and review of the literature. Cardiovasc Surg. 1994;2: 359-69.

3. Beaujeux RL, Reizine DC, Casasco A, et al. Endovascular treatment of vertebral arteriovenous fistula. Radiology. 1992;183:361-7.

4. Mortimer A, Stubbs E, Cookson D, et al. Delayed presentation of a vertebral arterio-venous fistula secondary to penetrating cervical trauma: endovascular management using coil embolisation - a case report. J Radiol Case Rep. 2009;3:9-15.

5. Hauck EF, Nauta HJ. Spontaneous spinal epidural arteriovenous fistulae in neurofibromatosis type-1. Surg Neurol. 2006;66:215-21.

6. Barkhordarian S. Stent graft repair of traumatic vertebral pseudoaneurysm with arteriovenous fistula. Vasc Endovasc Surg. 2007:41:153-7.

7. Geraci AR, Upson JF, Greene DG. Congenital vertebral arteriovenous fistula. JAMA. 1969;210:727-8.

8. Guglielmi G, Viñuela F, Duckwiler G, et al. High-flow, small-hole arteriovenous fistulas: treatment with electrodetachable coils. AJNR Am J Neuroradiol. 1995;16:325-8.

9. Bahar S, Chiras J, Carpena JP, et al. Spontaneous vertebro-vertebral arteriovenous fistula associated with fibro-muscular dysplasia. Report of two cases. Neuroradiology. 1984;26:45-9.

10. Kāhārā V, Lehto U, Ryymin $P$, et al. Vertebral epidural arteriovenous fistula and radicular pain in neurofibromatosis type I. Acta Neurochir. 2002;144: 493-6.

11. de Bray JM, Bertrand P, Bertrand F, Jeanvoine H. Spontaneous arteriovenous fistulas of the vertebral artery. Apropos of a case--review of the literature. Rev Med Interne. 1986;7:133-9.

12. Herrera DA, Vargas $S A$, Dublin AB. Endovascular treatment of traumatic injuries of the vertebral artery. Am J Neuroradiol. 2008;29(8):1585-9.

13. Stock U, Link J, Dutschke P. latrogenic vertebrojugular arteriovenous fistula. Anaesthesia. 1996;51(7):687-8. 
14. Yamamoto A, Suzuki K, Sakaida H, et al. Management of inadvertent vertebral artery injury due to central venous catheterization in a coagulopathic patient. Acute Med Surg. 2015;3(3):265-7.

15. Varga ZA, Gyori-Molnar I, Kollar L, et al. A surgically treated arteriovenous fistula between the vertebral artery and internal jugular vein after insertion of a central venous catheter for mitral valve replacement. J Thorac Cardiovasc Surg. 2002;123(3):575-7.

16. Surber R, Werner GS, Cohnert TU, et al. Recurrent vertebral arteriovenous fitula after surgical repair: treatment with a self-expanding stent-graft. J Endovasc Ther. 2003;10:49-53.

17. Kim YH, Gildenberg PL, Duchesneau PM. Angiographic evidence of spontaneous closure of nontraumatic arteriovenous fistula of the vertebral artery. Case report J Neurosurg. 1973;38:658-61.

18. Goodman SJ, Hasso A, Kirkpatrick D. Treatment of vertebrojugular fistula by balloon occlusion. Case report. J Neurosurg. 1975:43:362-7.

19. Gobin YP, Duckwiler GR, Viñuela F. Direct arteriovenous fistulas (carotidcavernous and vertebral-venous). Diagnosis and intervention. Neuroimaging Clin N Am. 1998;8:425-43.

20. Tenjin H, Kimura S, Sugawa N. Coil embolization of vertebro-vertebral arteriovenous fistula: a case report. Surg Neurol. 2005;63:80-3.

21. Deans WR, Bloch $S$, Leibrock $L$, et al. Arteriovenous fistula in patients with neurofibromatosis. Radiology. 1982;144:103-7.

22. Peeters FL. Endovascular treatment of spontaneous vertebro-vertebral fistulas. Rofo. 1990;153:724-5.

23. Tay KY, U-King-Im JM, Trivedi RA, et al. Imaging the vertebral artery. Eur Radiol. 2005:15:1329-43.

24. O'Shaughnessy BA, Bendok BR, Parkinson RJ, et al. Transarterial coil embolization of a high-flow vertebrojugular fistula due to penetrating craniocervical trauma: case report. Surg Neurol. 2005;64:335-40.

Ready to submit your research? Choose BMC and benefit from:

- fast, convenient online submission

- thorough peer review by experienced researchers in your field

- rapid publication on acceptance

- support for research data, including large and complex data types

- gold Open Access which fosters wider collaboration and increased citations

- maximum visibility for your research: over $100 \mathrm{M}$ website views per year

At $\mathrm{BMC}$, research is always in progress.

Learn more biomedcentral.com/submissions 